\title{
Analisis Hubungan Kerawanan Longsor Lahan dengan Penggunaan Lahan di Sub-Das Kali Arus Kabupaten Banyumas
}

\author{
Analysis of Relationship between Landslide Vulnerability and Land Use \\ in the Kali Arus Sub-watershed in Banyumas Regency
}

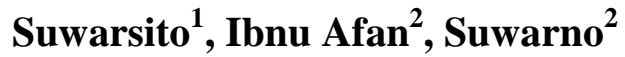 \\ ${ }^{1,2}$ Pendidikan Geografi - Universitas Muhammadiyah Purwokerto, Indonesia \\ ${ }^{1}$ suwarsito@ump.ac.id
}

\begin{abstract}
ABSTRAK
Penggunaan lahan di Sub-DAS (Daerah Aliran Sungai) Kali Arus sangatlah beragam yaitu untuk lahan pertanian dan non pertanian.. menganalisis hubungan kelas kerawanan longsorlahan dengan penggunaaan lahan di Sub-DAS Kali Arus Kabupaten Banyumas. Metode yang digunakan dalam penelitian ini adalah metode survei. Data penelitian ini meliputi data primer dan sekunder. Data primer berupa penggunaan lahan diperoleh dari survai dan Google Earth dan data sekunder berupa kerawanan longsorlahan. Teknik pengambilan sampel menggunakan total sampling, yaitu mengambil seluruh jenis penggunaan lahan di wilayah penelitian yang terdiri atas perkebunan, permukiman, sawah, sawah tadah hujan, rumput, dan tegalan. Pengolahan data dilakukan menggunakan Software ArcMap yaitu dengan memberikan warna yang berbeda pada setiap jenis pengunaan lahan dan arsiran pada setiap kelas kerawanan longsorlahan sesuai dengan kriteria yang sudah ditetapkan. Analisis data dilakukan dengan cara membuat overlay untuk mengetahui hubungan kerawanan longsorlahan dan penggunaan lahan di Sub-DAS (Daerah Aliran Sungai) Kali Arus. Hasil penelitian menunjukan bahwa penggunaan lahan pada kelas kerawanan longsorlahan sedang dan tinggi berbeda-beda. Hal ini dipengaruhi oleh berbagai factor, yaitu curah hujan, karakteristik jenis tanah dan topografi wilayah yang berbeda-beda. Adapun bentuk penggunaa lahan yang termasuk pada kelas kerawanan longsorlahan sedang adalah perkebunan/kebun, permukiman, sawah, sawah tadah hujan, tegalan/ladang, dan rumput yang meliputi wilayah Desa Petahunan dan Desa Semedo Kecamatan Pekuncen. Bentuk penggunaa lahan yang termasuk pada kelas kerawanan longsorlahan tinggi adalah perkebunan, sawah, permukiman, dan tegalan yang meliputi wilayah Desa Karangkemiri Kecamatan Pekuncen, Desa Kedungurang Kecamatan Gumelar, dan Desa Gancang Kecamatan Gumelar.
\end{abstract}

Kata Kunci: Penggunaan lahan, Daerah Aliran Sungai Kali Arus, Kerawanan, Longsorlahan.

\begin{abstract}
Land use in Kali Arus Sub- watershed is very diverse, namely for agricultural and nonagricultural land. Analyzing the relationship between landslide hazard class and land use in Kali Arus Sub-watershed, Banyumas Regency. The method used in this study is a survey method. This research data includes primary and secondary data. Primary data in the form of land use were obtained from surveys and Google Earth and secondary data in the form of landslides. The sampling technique uses total sampling, which is to take all types of land use in the study area consisting of plantations, settlements, rice fields, rainfed fields, grasses, and fields. Data processing is performed using ArcMap Software,
\end{abstract}


namely by providing a different color on each type of land use and shading in each class of landslide vulnerability in accordance with established criteria. Data analysis was carried out by overlaying to determine the relationship between landslide vulnerability and land use in the Kali Arus Sub-watershed. The results showed that land use in moderate and high landslide hazard classes was different. This is influenced by various factors, namely rainfall, soil type characteristics and regional topography. The forms of land use included in the medium landslide hazard class are plantations / gardens, settlements, paddy fields, rain-fed rice fields, dry fields / fields, and grasses that cover the areas of Petahunan Village and Semedo Village, Pekuncen District. The forms of land use that belong to the class of high landslide vulnerability are plantations, rice fields, settlements, and dry fields which cover the area of Karangkemiri Village, Pekuncen District, Kedungurang Village, Gumelar District, and Gancang Village, Gumelar District.

Keywords: Land use, Kali Arus Sub-watershed, Hazard, Landslide.

\section{PENDAHULUAN}

Penggunaan lahan di Sub-DAS (Daerah Aliran Sungai) Kali Arus sangatlah beragam di antaranya untuk lahan pertanian dan non pertanian. Berbagai jenis lahan pertanian dapat ditemukan di wilayah Sub-DAS Kali Arus, yaitu sawah, sawah tadah hujan, perkebunan, dan ladang/tegalan. Sedangkan lahan non pertanian di Sub-DAS Kali Arus terdiri dari permukiman dan lahan padang rumput.

Penggunaan lahan merupakan hasil usaha manusia dalam mengelola sumber daya yang tersedia untuk memenuhi berbagai kebutuhannya (Windianti, 2008). Penggunan lahan di suatu wilayah merupakan pencerminan upaya (tindakan) dan interkasi manusia dalam memanfaatkan dan mengelola sumber daya alam beserta kondisi lingkungan yang menyertainya. Oleh karena itu, penggunaan lahan di suatu wilayah bersifat dinamis (Utoyo, 2012)

Penggunaan lahan baru atau pengalih fungsian lahan pada umumnya dimanfaatkan untuk kepentingan permukiman. Walaupun lahan pemukiman tersebut berada pada kelas kerawanan longsorlahan sedang maupun tinggi dan kurang tepat dijadikan sebagai permukiman, namun karena kebutuhan lahan untuk pemukiman semakin banyak, manusia tetap melakukan pengalih fungsian lahan untuk pemukiman. Akibat dari pengalih fungsian lahan tersebut dapat merubah bentuk lereng dengan cara pengeprasan dan penimbunan lereng. Usaha pengeprasan dan penimbunan lereng tersebut justru menjadikan lereng semakin terjal dan meningkatknya kerawanan longsorlahan. Hilangnya vegetasi utama pada lereng tersebut juga dapat mengganggu keseimbangan tanah dan mengurangi daerah resapan air sehinga tanah pada lereng akan lebih mudah bergerak dan terbawa air ketika hujan mengguyur kawasan tersebut (Barus, 1999). Penelitian ini dilakukan untuk menganalisis hubungan kelas kerawanan longsorlahan dengan penggunaaan lahan di Sub-DAS Kali Arus Kabupaten Banyumas.

\section{METODE}

Penelitian ini menggunakan metode survai. Metode survai digunakan untuk meneliti secara langsung hubungan sebab akibat antara kelas kerawanan longsorlahan dengan penggunaan lahan di Sub-DAS Kali Arus Kabupaten Banyumas. Data yang digunakan dalam penelitian ini meliputi data primer dan sekunder. Data primer berupa penggunaan lahan diperoleh dari survai dan Google Earth dan data sekunder berupa kerawanan longsorlahan. Teknik pengumpulan data penggunaan lahan diperoleh dengan 
cara membaca dan menganalisis Citra Satelit yang diunduh dari Google Earth tahun 2017 Sub-DAS Kali Arus dan survai lapangan. Data kelas kerawanan longsorlahan diperoleh dari data sekunder peta kerawanan longsorlahan Sub-DAS Kali Arus bersumber dari penelitian, Suwarno dan Sutomo, 2017.

Teknik pengambilan sampel menggunakan total sampling, yaitu mengambil seluruh jenis penggunaan lahan di wilayah penelitian yang terdiri atas perkebunan, permukiman, sawah, sawah tadah hujan, rumput, dan tegalan. Pengolahan data dilakukan menggunakan Software ArcMap yaitu dengan memberikan warna yang berbeda pada setiap jenis pengunaan lahan dan arsiran pada setiap kelas kerawanan longsorlahan sesuai dengan kriteria yang sudah ditetapkan. Analisis data dilakukan dengan cara membuat overlay untuk mengetahui hubungan kerawanan longsorlahan dan penggunaan lahan di Sub-DAS Kali Arus.

\section{HASIL DAN PEMBAHASAN}

Lokasi penelitian di Sub DAS Kali Arus, secara administrasi terletak di sebagian Kecamatan Gumelar dan Pekuncen, Kabupaten Banyumas. Secara astronomis daerah penelitian terletak pada posisi $7^{0} 20^{\prime} 20,83^{\prime \prime}$ - $7^{0} 24^{\prime} 30,56^{\prime \prime} \mathrm{LS}$ dan $109^{0} 00^{\prime} 21,52^{\prime \prime}$ - $109^{\circ} 03^{\prime} 34,21^{\prime \prime}$ BT. Secara geografi Sub-DAS Kali Arus terletak di Kabupaten Banyumas, yang mencakup 2 kecamatan yaitu Kecamatan Pekuncen dan Kecamatan Gumelar. Sungai Kali Arus mengalir dari hulu (puncak perbukitan Seraya Utara) dan menuju ke hilir bermuara di Sungai Tajum.

Penggunaan lahan diperoleh dari interpertasi Peta Rupa Bumi Indonesia lembar nomor 130-611 dan 130-613, serta pengamatan lapangan. Penggunaan lahan di wilayah penelitian terdiri atas padang rumput, sawah, sawah tadah hujan, kebun, permukiman, dan tegalan. Tabel 1 menyajikan luasan penggunaan lahan dan kejadian longsorlahan di SubDAS Kali Arus.

Tabel 1. Luasan penggunaan lahan dan banyaknya kejadian longsorlahan

\begin{tabular}{rlrcr}
\hline \multirow{2}{*}{ No } & \multirow{2}{*}{ Penggunaan Lahan } & Luas (ha) & \multicolumn{3}{c}{ Titik Longsor } \\
\cline { 4 - 5 } & & & Jumlah & Persentase (\%) \\
\hline 1 & Padang Rumput & 0,76 & 0 & 0,00 \\
2 & Perkebunan/Kebun & 1229,39 & 25 & 52,08 \\
3 & Permukiman & 316,04 & 17 & 35,42 \\
4 & Sawah & 22,04 & 0 & 0,00 \\
5 & Sawah Tadah Hujan & 382,80 & 6 & 12,50 \\
6 & Tegalan/Ladang & 79,75 & 0 & 0,00 \\
& JUMLAH & 2029,78 & 48 & 100,00 \\
\hline (Sumber: Suwarno dan Sutomo, 2017) & & &
\end{tabular}

(Sumber: Suwarno dan Sutomo, 2017)

Berdasarkan Tabel 1 penggunaan lahan terluas terdapat pada penggunaan lahan perkebunan dengan luas 1229,39 Ha dengan jumlah titik longsor 25 atau 52,08 \% dan yang tersempit adalah penggunaan lahan padang rumput dengan luas $0,76 \mathrm{Ha}$.

Analisis kelas kerawanan longsorlahan menggunakan parameter penilaian kawasan rawan longsor yang dikeluarkan oleh Departemen Pekerjaan Umum yaitu PMPU No. 22/PRT/M/2007 yangmengklasifikasi lahan rawan longsorlahan berdasarkan pada faktor klimatologi, geomorfologi, geologi, tanah, dan penggunaan lahan.

Menurut Suwarno dan Sutomo (2017), faktor-faktor kerawanan longsorlahan di daerah penelitian terdiri atas 11 variabel yaitu tebal curah hujan, kejadian longsorlahan, 
lereng, relief, tebal lapukan, tekstur, permeabilitas, jenis batuan, struktur lapisan batuan, gempa, dan penggunaan lahan. Dari 11 variabel penyebab kerawanan di Sub-DAS Kali Arus diklasifikasikan menjadi 2 (dua) kelas kerawanan longsorlahan yaitu kelas kerawanan sedang dan kelas kerawanan tinggi (Tabel 2).

Tabel 2. Klasifikasi kelas kerawanan dan banyaknya kejadian longsorlahan

\begin{tabular}{ccccc}
\hline \multirow{2}{*}{ No } & \multirow{2}{*}{ Kelas Kerawanan } & Luas (Ha) & \multicolumn{2}{c}{ Titik Longsor } \\
\cline { 4 - 5 } & & \multirow{2}{*}{ Jumlah } & Persentase (\%) \\
\hline 1 & Sedang & 381,67 & 5 & 10,41 \\
2 & Tinggi & 1648,11 & 43 & 89,59 \\
& Jumlah & & 48 & 100,00 \\
\hline
\end{tabular}

Sumber : Suwarno dan Sutomo (2017)

Berdasarkan Tabel 2 terlihat bahwa kelas kerawanan longsorlahan tinggi terdapat pada 43 titik longsor $(89,59 \%)$ dengan luas 1648,11 Ha. Wilayah dengan kelas kerawanan longsorlahan tinggi meliputi Desa Karangkemiri Kecamatan Pekuncen, Desa Kedungurang Kecamatan Gumelar, dan Desa Gancang Kecamatan Gumelar. Sedangkan kelas kerawanan longsorlahan sedang terdapat pada 5 titik longsor $(10,41 \%)$ dengan luas 381,67 Ha. Wilayah kelas kerawanan longsorlahan sedang meliputi Desa Petahunan dan Desa Semedo Kecamatan Pekuncen.

Pada wilayah Sub-DAS Kali Arus terdapat 6 jenis penggunaan lahan. Keenam penggunaan lahan tersebut dihubungkan dengan 2 kelas kerawanan longsorlahan di SubDAS Kali Arus. Hubungan dari kedua variebel tersebut akan menghasilkan data penggunaan lahan pada berbagai kelas kerawanan longsorlahan di Sub-DAS Kali Arus. Hubungan dua variebel tersebut diperoleh dengan menggunakan perangkat ArcMap untuk mengolah data berupa peta penggunaan lahan dan kerawanan longsorlahan, kemudian data tersebut dianalisis dengan cara overlay untuk mengetahui luasan masing-masing penggunaan lahan di tiap kelas kerawanan longsorlahan. Hasil overlay disajikan pada Tabel 3 dan Gambar 1.

Tabel 3. Hubungan Penggunaan Lahan dengan Kerawanan Longsorlahan

\begin{tabular}{llcccc}
\hline \multirow{2}{*}{$\begin{array}{c}\text { Bentuk } \\
\text { No }\end{array}$} & $\begin{array}{c}\text { Penggunaan } \\
\text { Lahan }\end{array}$ & \multicolumn{3}{c}{ Kelas Kerawanaan Longsorlahan } \\
\cline { 3 - 6 } & \multicolumn{1}{c}{ Sedang } & \multicolumn{2}{c}{ Tinggi } \\
\cline { 3 - 6 } & Luas (Ha) & Persentase (\%) & Luas (Ha) & Persentase (\%) \\
\hline 1 & Permukiman & 127,17 & 33,37 & 205,34 & 12,45 \\
2 & Rumput & 0,71 & 0,18 & 0 & 0 \\
3 & Perkebunan/kebun & 142,38 & 37,36 & 1059,89 & 64,3 \\
4 & Sawah & 86,8 & 22,77 & 321,42 & 19,5 \\
5 & Sawah Tadah Hujan & 22,04 & 5,78 & 0 & 0 \\
6 & Tegalan/ladang & 1,97 & 0,51 & 61,58 & 3,73 \\
& Jumlah & $\mathbf{3 8 1 , 0 7}$ & $\mathbf{1 0 0 , 0 0}$ & $\mathbf{1 6 4 8 , 2 3}$ & $\mathbf{1 0 0 , 0 0}$ \\
\hline
\end{tabular}

Sumber : Peta RBI Kab. Banyumas Lembar 130-8611.130-8613 Skala 1:25.000. 
PETA HUBUNGAN KERAWANAN LONGSORLAHAN DENGAN PENGGUNAAN LAHAN DI SUB-DAS KALI ARUS KAB. BANYUMAS TAHUN 2018

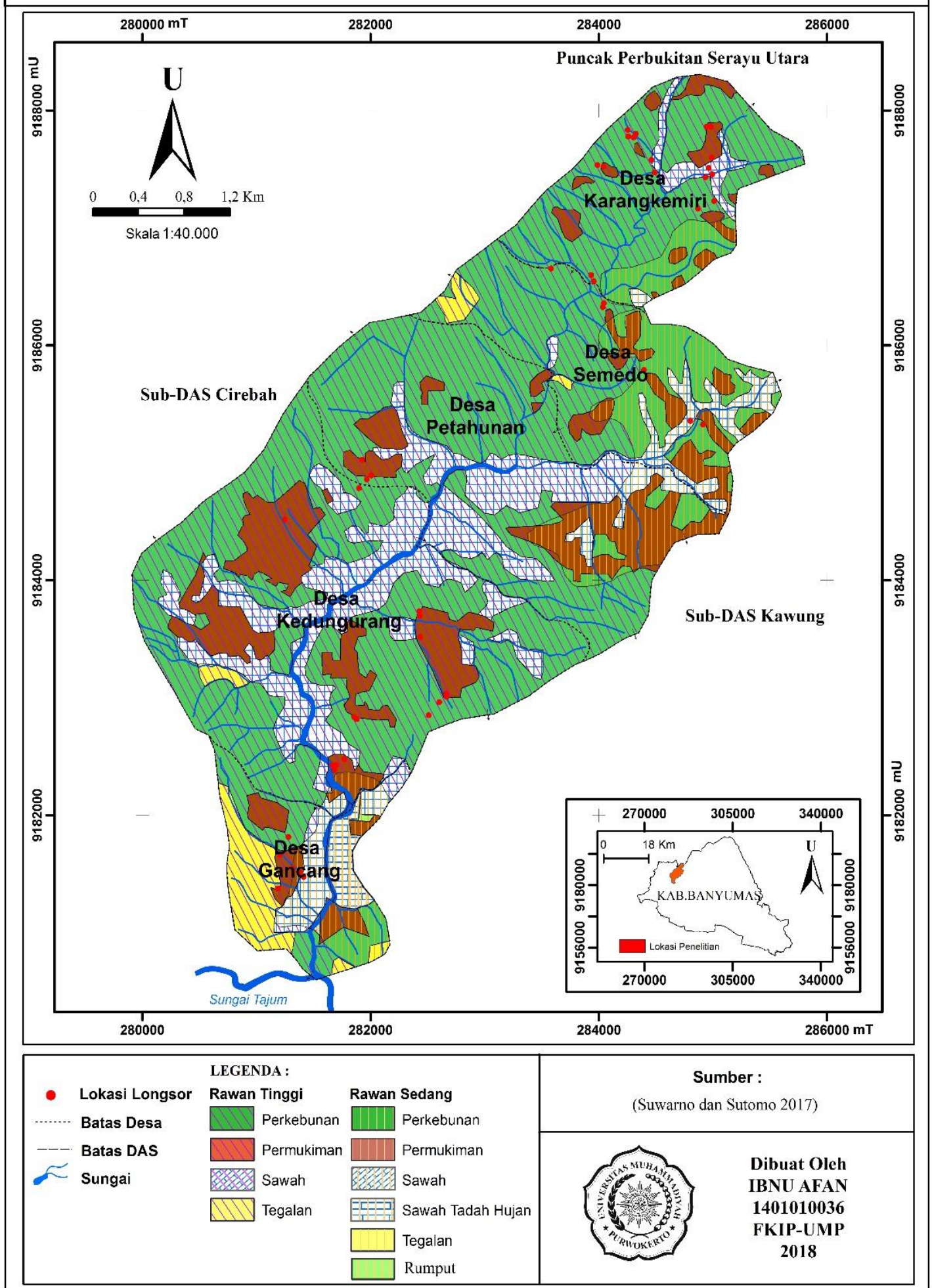

Gambar 1. Peta Hubungan Kerawanan Longsorlahan dengan Penggunaan Lahan SUB-DAS Kali Arus Kab, Banyumas (Suwarno dan Sutomo, 2017) 
Berdasarkan data pada Tabel 3 terlihat bahwa penggunaan lahan pada kelas kerawanan longsorlahan sedang dan tinggi berbeda-beda. Hal ini dipengaruhi oleh berbagai faktor, yaitu curah hujan, karakteristik jenis tanah dan topografi wilayah yang berbeda-beda. Penggunaan lahan pada kelas kerawanan longsorlahan sedang antara lain untuk perkebunan/kebun dengan luas 142,38 ha $(37,36 \%)$, permukiman dengan luas 127,17 ha $(33,37 \%)$, sawah dengan luas 86,8 ha $(22,77 \%)$, sawah tadah hujan dengan luas 22,04 ha $(5,78 \%)$, tegalan/ladang dengan luas 1,97 ha $(0,51 \%)$, dan rumput dengan luas 0,71 ha $(0,18 \%)$. Dari keenam jenis penggunaan lahan pada kelas kerawanan longsor lahan sedang didominasi oleh penggunaan lahan perkebunan dan permukiman. Berdasarkan kriteria daerah tersebut sebaran penggunan lahan dipengaruhi oleh kemiringan lereng. Suwarno (2014) mengemukakan bahwa sebaran longsorlahan salah satunya disebabkan oleh faktor penggunaan lahan.

Jenis penggunaan lahan pada kelas kerawanan longsorlahan tinggi adalah perkebunan/kebun dengan luas 1059,89 ha (64,3\%), sawah dengan luas 321,42 ha (19,5\%), permukiman dengan luas 205,34 ha $(12,45 \%)$, dan tegalan dengan luas 61,58 $(3,75 \%)$. Jenis penggunaan lahan sawah tadah hujan dan rumput tidak terdapat pada wilayah dengan kelas kerawanan longsorlahan tinggi. Berdasarkan hasil survai di lapangan menunjukkan bahwa penggunaan lahan untuk sawah tadah hujan dan rumput pada kelas kerawanan tinggi dapat memicu terjadinya longsorlahan.

Pada wilayah penelitian di Sub-DAS Kali Arus terdapat 6 jenis bentuk penggunaan lahan. Keenam jenis bentuk penggunaan lahan tersebut terdapat dalam 2 kelas kerawanan longsorlahan. Masing-masing kelas kerawanan longsorlahan memiliki satu bentuk penggunaan lahan yang mendominasi wilayah tersebut. Jenis penggunaan lahan perkebunan/kebun adalah jenis penggunaan lahan terluas pada kelas kerawanan longsor lahan sedang, terluas kedua permukiman, terluas ketiga sawah, terluas keempat sawah tadah hujan, terluas kelima tegalan/ladang dan terluas keenam rumput. Pada wilayah tersebut tidak banyak memiliki lereng terjal, yaitu kemiringan lerengnya hanya antara 8 $15 \%$. Wilayah dengan kelas kerawanan sedang terdapat pada bagian Timur dan Selatan Kali Arus. Wilayah tersebut masuk ke dalam kategori kelas kerawanan longsorlahan sedang, karena sebagian besar wilayah termasuk kedalam wilayah dengan kemiringan lereng $8-15 \%$ dan $\leq 25 \%$ dengan topografi wilayah datar bergelombang, datar berombak dan berbukit, curah hujan antara 2000-3000 mm/th dan $4000 \mathrm{~mm} / \mathrm{th}$ dan mulai banyaknya aktifitas manusia yang mengganggu kestabilan lereng. Wilayah tersebut meliputi Desa Petahunan dan Desa Semedo Kecamatan Pekuncen.

Jenis penggunaan lahan perkebunan/kebun merupakan jenis penggunaan lahan terluas pada kelas kerawanan longsorlahan tinggi. Penggunaan lahan terluas kedua adalah sawah, terluas ketiga adalah permukiman, dan terluas keempat adalah tegalan. Wilayah dengan kelas kerawanan longsorlahan tinggi meliputi Desa Karangkemiri Kecamatan Pekuncen, Desa Kedungurang Kecamatan Gumelar, dan Desa Gancang Kecamatan Gumelar. Wilayah tersebut masuk kedalam kelas kerawanan tinggi, karena pada wilayah tersebut banyak memiliki lereng terjal, lereng berkisar antara (15-25\%) hingga ( $\geq 40 \%)$ dengan topografi berbukit, bukit, hingga bergunung, dan memiliki curah hujan tinggi antara 3000-4000 mm/th. Kelas kerawanan longsorlahan tertinggi terdapat di bagian tengah wilayah penelitian, tingginya aktifitas manusia yang mengganggu kestabilan lereng seperti pemotongan dan penimbunan lahan. Hal ini membuat daerah tersebut digolongkan dalam kelas kerawanan longsor lahan tinggi.

Hasil penelitian ini sesuai dengan pendapat Rupaka dkk. (2015) bahwa sebaran longsorlahan tergantung karakteristik wilayah setempat yang juga di pengaruhi curah hujan, vegetasi, dan peningkatan beban massa tanah. Beban massa tanah yang bertambah 
biasanya diakibatkan adanya pengalih fungsian lahan seperti pertanian ke permukiman. Penggunaan lahan dengan vegetasi yang tidak sesuai dengan kondisi fisik daerah juga menyebabkan masalah lingkungan terutama kejadian longsorlahan. Vegetasi mempunyai pengaruh yang bersifat melawan terhadap pengaruh faktor-faktor lain yang erosif seperti hujan, topografi dan karakteristik tanah (Indracahya dkk, 2015). Vegetasi yang terdapat pada perkebunan/kebun harus sesuai dengan kondisi fisik daerahnya, misalnya pada bagian lereng, tanaman yang ditanam sebaiknya ditanami tanaman tahunan yang memiliki sistem perakaran yang dalam seperti pinus, sengon, jati, mahoni, cengkeh dan lain sebagainya. Pada wilayah tersebut sebaiknya bukan ditanami tanaman yang membutuhkan tanah gembur, karena tanah gembur akan mempercepat terjadinya longsorlahan.

\section{KESIMPULAN}

Berdasarkan hasil penelitian dapat disimpulkan bahwa penggunaan lahan pada kelas kerawanan longsorlahan sedang dan tinggi berbeda-beda. Hal ini dipengaruhi oleh berbagai factor, yaitu curah hujan, karakteristik jenis tanah dan topografi wilayah yang berbeda-beda. Adapun bentuk penggunaa lahan yang termasuk pada kelas kerawanan longsorlahan sedang adalah perkebunan/kebun, permukiman, sawah, sawah tadah hujan, tegalan/ladang, dan rumput yang meliputi wilayah Desa Petahunan dan Desa Semedo Kecamatan Pekuncen. Bentuk penggunaa lahan yang termasuk pada kelas kerawanan longsorlahan tinggi adalah perkebunan, sawah, permukiman, dan tegalan yang meliputi wilayah Desa Karangkemiri Kecamatan Pekuncen, Desa Kedungurang Kecamatan Gumelar, dan Desa Gancang Kecamatan Gumelar.

\section{DAFTAR PUSTAKA}

Barus, B. (1999). Pemetaan Bahaya Longsoran Berdasarkan Klasifikasi Statistik Perubah Tunggal Menggunakan SIG: Studi Kasus Daerah Ciawi-Puncak-Pacet, Jawa Barat. Jurnal Ilmu Dan Lingkungan. Vol 2 No. 1, Hal 7-16.

Indracahya, M.B., Suwarno, dan Sutomo (2015) Kajian Penggunaan Lahan Terhadap Kerawanan Longsorlahan Di SUB-DAS Logawa Kabupaten Banyumas, Jurnal Prosiding Seminar Nasional Pendidikan Geografi FKIP UMP. 13 Juni 2015, ISBN 978-602-74194-0-7.

Rupaka, A.P.G., Suharyanto, Sudarno (2015) Analisis Kesesuaian Penggunaan Lahan Pada Daerah Rawan Tanah Longsor Di Kabupaten Tegal, Jurnal Presipitasi Vol. 12 (2): $52-60$.

Suwarno, (2014). Model Pengelolaan lahan pada Wilayah Rawan Longsorlahan di Kecamatan Pekuncen Kabupaten Banyumas, Disertasi, Program Doktor Fakultas Geografi Universitas Gadjah Mada. Yogyakarta.

Suwarno dan Sutomo, (2017). Model Analog Potensi Bencana Alam Longsorlahan Dengan Pendekatan Geomorfologikal Di Sub DAS Kali Arus Kabupaten Banyumas.Laporan Ahkir Penelitian Produk Terapan. Program Studi Geografi FKIP UMP. Purwokerto.

Utoyo, B. (2012). Dinamika Penggunaan Lahan di Wilayah Perkotaan (Studi Kota Bandar Lampung). Skripsi. Universitas Lampung. Lampung.

Windianti, I. (2008). Pengaruh Penggunaan Tata Guna Lahan di DAS Keduang Ditinjau Dari Aspek Hirologi. Skripsi. Universitas Sebelas Maret Surakarta. 